\title{
Chapter 9: Reconceiving Federal-State-Regional Arrangements in Health
}

\section{Andrew Podger}

\section{Introduction}

Australia has a generally good health system, but it is changing in response to existing challenges and it faces new challenges which require substantial reform if the system is to remain affordable and effective. The system is huge, with expenditure in health accounting for around 9.7\% of Australia's annual gross domestic product (GDP). It is difficult to imagine an area of public policy and service delivery with which the average Australian citizen would have more contact, or of greater importance to the community. As a result, substantial reform is difficult - politically, financially and logistically.

This chapter examines some of the options for reform and restructuring of the health system to meet new challenges, in the context of our current federal system. Most of my perspectives are from practical experience at a federal level, rather than any particular theory of how our federal system should work. First I will examine some of the principles of effective and responsive government including some new ways in which government can and often does achieve results, working across traditional institutional boundaries. But despite improvements in whole-of-government collaboration, for major ongoing national priorities like health, poor institutional structures can still present major practical obstacles to achieving efficient and effective outcomes. This is explained in the second part of the chapter. The challenges lie at both the national level, where we need the accountability and efficiency of a system based on national funding and national standards - and at the regional and local levels - at which health services need to be adapted and delivered, but where our institutional infrastructure is comparatively weak: there is a need for greater directness, simplicity and clarity in the relationships between these levels.

The third part of the chapter talks a little more about what is needed at each level of the health system, particularly the local and regional levels. It becomes clear that we have to start considering some new institutional options, within our current federal context, if we want to maintain the best possible health system into the future. The model I propose would be more patient-focussed than the one we have now, but would also have in-built incentives to improve efficiency. It would also more effectively address equity, in my view, giving 
more resources to regions and communities (including Indigenous communities) that most need additional support.

The choice facing governments is not one between theoretical, idealised models of new systems, on the one hand, and small practical incremental solutions to immediate problems on the other. It is a mixture of both. If a more incremental approach is pursued, it is important also to have a clear strategic direction to avoid ad hocracy; if government is willing to consider systemic change, it must include measures that deliver tangible improvements along the way as well as lead to structures with better in-built incentives for improved performance. Clearly my preference is for the latter approach.

\section{Principles for more effective governance}

A first general principle for helping make government effective and responsive is the 'subsidiarity principle' - also mentioned by other authors in this volume (see Brown, Head, Wiltshire, Smith this volume). Based on what our national Productivity Commission has said over many years (e.g. Productivity Commission 1998), my own definition of the subsidiarity principle is that 'power should be devolved to the lowest level of government where there is shared community interest'. The principle is about distinguishing clearly who should be responsible for what, as well as supporting vertical fiscal balance, so that each level of government is able to raise and control the funds necessary to meet the policy requirements for which it is accountable.

In practice, however, 'subsidiarity' is not an absolute principle - it has to fit into the pragmatic realities of day-to-day government. As a former head of Commonwealth Government departments, including Health as well as Housing and Regional Development, I learned it was very useful, in a practical sense, to understand that the relationships between different parts of the federal system were much like the relationships between any set of organisations. A Canadian expert once distinguished between those matters that you can control; those you can only influence; and those matters which lie in the control of others, which it is wise to appreciate as you decide how to go about your own business (Smith 1992). While there are advantages in clarifying responsibilities - that is, who controls what - there are still always boundary areas and grey areas, where one jurisdiction wants to influence another. As boundaries shift over time, it is also wise to have an appreciation of those areas that are under the control of the other party, to ensure that attempts to influence are based on informed judgments.

So, if the Commonwealth wants to influence aspects of health or housing or city planning or community services it needs a real appreciation of those fields of social policy and management. Equally, it is important for state or local governments to have an appreciation of national policy concerns that might 
affect the areas that are under their control, such as international obligations or national equity issues. It is not just a matter of setting who controls what, but thinking carefully of how you influence and appreciate the things that other levels of government have to control.

Another practical reality, which can assist the ability of government to work across traditional institutional boundaries, is 'horizontal' rather than 'vertical' management of programs and projects. Horizontal management means 'connected government', or 'joined-up' government, in which we find new ways to ensure that all the different parts of government overcome their institutional separations and come together to efficiently and effectively play their part. The greater interest in connectivity and horizontal government in recent years should not be seen as just a fad - it has many recognised long-term drivers, across many policy areas, on a worldwide basis. These include the increasing demands of citizens; the complexity of modern social problems; the pressure on public budgets; the impact of new information and communications technologies, giving both the increased technical capacity to connect and a related increase in expectations that we will use that capacity; and active experimentation by governments in new ways to meet these challenges and deliver services (Lindquist 2000).

Again, however, there are limits and risks to using horizontal approaches. We identified some of these in a recent major report on 'connecting government' at a Commonwealth level (Management Advisory Committee 2004). If you try to connect everything to everything else, all the time, it can be very costly and time-consuming, and not very efficient. A great deal of effort can be put into cooperative efforts that were always doomed to fail, because there were competing political and community agendas within the control of other parties. Alternatively, if those agendas are not taken seriously and are instead overridden in the push to consensus, there is the danger of 'groupthink' - that is, of pressuring everyone involved to agree, rather than to ensure that the different perspectives are robustly considered. This can result in lowest common denominator solutions. Finally, establishing complex arrangements to involve many parties in a solution, may not be the most efficient and effective way of dealing with a routine, straightforward issue.

Of the many issues relevant to deciding when and how to apply the principles of connected government, two are particularly important when thinking about the problems with our current federal system - the structures and processes to be used, and the imperatives for external engagement, meaning direct engagement with the community and others outside government. Table 9.1 sets out that there is no fixed approach, when it comes to structures and processes. Different whole-of-government tasks require different structures. 
Table 9.1. Matching Whole-of-Government Structures to Different Tasks

\begin{tabular}{|l|c|c|c|c|c|}
\hline Task Structure & $\begin{array}{c}\text { Policy } \\
\text { Development }\end{array}$ & $\begin{array}{c}\text { Program } \\
\text { Design / } \\
\text { Review }\end{array}$ & $\begin{array}{c}\text { Program } \\
\text { Management/ } \\
\text { Service } \\
\text { Delivery }\end{array}$ & $\begin{array}{c}\text { Cross } \\
\text { Jurisdiction/ } \\
\text { Cross Sector }\end{array}$ & $\begin{array}{c}\text { Crisis } \\
\text { Management }\end{array}$ \\
\hline $\begin{array}{l}\text { Inter-Departmental } \\
\text { Committee (IDC) }\end{array}$ & $\mathrm{H}$ & $\mathrm{M}$ & $\mathrm{L}$ & $\mathrm{M}$ & $\mathrm{H}-\mathrm{M}$ \\
\hline Taskforce & $\mathrm{H}$ & $\mathrm{H}$ & $\mathrm{H}$ & $\mathrm{H}-\mathrm{M}$ & $\mathrm{M}-\mathrm{L}$ \\
\hline Joint team & $\mathrm{H}-\mathrm{M}$ & $\mathrm{H}-\mathrm{M}$ & $\mathrm{M}$ & $\mathrm{M}-\mathrm{L}$ & $\mathrm{L}$ \\
\hline Agency arrangements & $\mathrm{L}$ & $\mathrm{L}$ & $\mathrm{H}$ & $\mathrm{M}-\mathrm{L}$ & $\mathrm{L}$ \\
\hline Frontier agencies & $\mathrm{H}$ & $\mathrm{H}$ & $\mathrm{H}$ & $\mathrm{L}$ & $\mathrm{L}$ \\
\hline
\end{tabular}

$\mathrm{H}=$ high relevance

$\mathrm{M}=$ medium relevance

$\mathrm{L}=$ low relevance

Source: Management Advisory Committee 2004, p.42 (Table 2.6)

The Management Advisory Committee report from which this table is drawn, focussed primarily on whole-of-government activity within a single level of government. But the message from this table would apply equally to inter-governmental structures and processes. The message is that horizontal management is easiest and most effective when dealing with time-limited projects. If you want to move away from traditional agency arrangements, and instead use IDCs and taskforces (or inter-governmental committees), for example, it is better when you are dealing with individual projects. In a modern world, in most government departments, there is also growing interest in thinking about program management as a series of projects. Accordingly, this approach to policy implementation - implementing policy project by project - also lends itself to being able to more easily pursue 'connectedness'. However, if you are dealing with ongoing programs - such as health programs in general, or natural resource management programs in general - then more traditional agency arrangements still tend to remain a better arrangement, in which a deliberate attempt is made to line up who is responsible for what, and where inter-agency (or inter-governmental) committees play more of a support role rather than a direct management role. So, notwithstanding the interest and the great potential of 'connected' or 'joined up' government in many areas, there are practical limits to this horizontality approach, and there are still advantages in trying to define the differing roles and responsibilities of different agencies reasonably firmly, where you can.

Because 'connected government' is partly a response to community demands, there are also serious issues about how connected government then deals with community engagement. These issues relate particularly to the political accountability and legitimacy of new types of structures. Whole-of-government initiatives, including ones involving multiple levels of government, often entail commitments to take into account the views of particular stakeholders more 
seriously than before - yet they must also preserve the responsibility of government(s) to the broader public interest. This can be a difficult exercise, especially for structures or institutions that have been formed on a relatively temporary and flexible basis.

An important part of community engagement is careful assessment of the views of the different interest groups that are presented. There are challenges involved in balancing complexity and consistency, where there is a need to respond to individual or community needs and preferences, while adhering to the policy objective of the broader - possibly national - community interests involved. Of particular relevance to reform in the health system, and some other service delivery areas, is the growing challenge of being responsive to a community or area or to individuals in ways that traditional services have not been able to achieve. An important success factor highlighted in the Management Advisory Committee report is having 'clout on the ground'. At the end of the day, there must be somebody there with authority and capability in local management, and with the necessary legitimacy and standing in the local community, to carry the outcomes into effect. Connected government can help provide these local actors - be they public servants or community representatives or both - with the authority from 'on high' to be able to act, but the local resources still need to be there, to have local legitimacy, and usually to be there longer than the lifespan of any single project.

This has been particularly demonstrated in Aboriginal affairs, but from my own experience it is important in any area of regional development. If you want to have regional development of a Commonwealth interest, you need to have a Commonwealth person at that regional level who has some clout and the capacity to negotiate and be able to act.

What lessons do we draw from these principles, for the current structures of public administration in our federal system? First, even in the age of cooperation and intergovernmental collaboration, we should not throw out the subsidiarity principle. It is important to clarify who is responsible for what, when talking about ongoing responsibilities, to the extent this is possible. But secondly, there will always still be boundaries between levels of government in any system, however it is reformed; and so we will need to have ongoing consultative machinery to ensure appreciation as well as management of those boundaries. Third, whole-of-government approaches can be used to improve government responsiveness, and share responsibility, where it is important and efficient to use these approaches to deal with challenges in a timely fashion - especially in relation to project management crises. But fourthly, the political pressure for these 'joined-up' solutions is also more long-term and enduring than can simply be met by shorter-term collaborations. And fifthly, in all of this, there is a need, however we do it, for greater capacity at the local/regional level - including 
Commonwealth capacity at that local/regional level - to develop and deliver better outcomes in the many areas where important national interests are at stake, along with those historically regarded as local and state ones.

\section{New approaches in health policy and services}

When we apply these principles to Australia's health system, the need for a new strategic approach becomes clear. Health is as much an industry as a system. In most countries, and certainly in Australia, health is certainly not a centrally designed, or hierarchically managed system. Participants, both consumers and providers, exercise a considerable degree of independence. The health system nonetheless is dominated by government, as funder and regulator, and frequently as the provider of health services themselves. While the system should, and will, remain a mixed 'public' and 'private' system, some of the key issues surround what it is best for government to do, with the focus on regulating, funding and purchasing health services. Under a reformed system, it would continue to matter less whether services themselves were provided privately or publicly, provided these regulatory, funding and purchasing arrangements were effective and more directly accountable.

Elsewhere I have set out some of the evidence that our health system actually performs quite well, on international standards (Podger 2006a and b). However this provides no room for complacency, because the challenges continue to mount. Indeed the system is already changing in response to these challenges, which increases our need to map clearly where we want it to go, rather than risk some of our current advantages by responding in ways that are disorganised or ad hoc. There are at least five major structural problems with the current system:

- A lack of patient-oriented care which crosses service boundaries easily, with funds following patients, particularly those with chronic diseases, the frail aged and Indigenous people. This is becoming increasingly important with our increasing life expectancy, and the big change over the last 30 years in the proportion of our population that is living longer after reaching the age of 50. The consequence is that there are many more frail aged people in our population, and many more people surviving heart disease, or cancer, and then living on under complex health regimes. A key issue for Australia's health system concerns people who are chronically ill or frail aged who move about the whole system - in and out of hospitals, on and off pharmaceuticals, receiving support in nursing homes, and getting support in their community. An increasing proportion of citizens cross all the traditional boundaries that have separated different service providers in the health system, both organisationally and geographically. Boundary issues are becoming far more important these days than they ever were in the past. 
- Allocative inefficiency, in which the allocation of funding between different types of care is not always geared towards achieving the best health outcomes possible, including in the ability of communities to invest directly in prevention and community health strategies as opposed to simply receiving funding for medical services (Menadue 2000, 2003). There are presently obstacles to our ability to shift resources within the system to enable individuals or communities to allow different mixes of service that reflect different needs.

- Poor use of information technology, where better investments and usage could not only reduce administrative costs and costs of duplicate testing, but also support more continuity of care, better identification of patients at risk, greater safety and more patient control.

- Poor use of competition, with an uneven playing field in acute care, a reluctance to use competition to ensure best access to medical services at reasonable cost, and less choice than should be possible, particularly in aged care.

- Workforce supply constraints, and increasing demand.

Every one of these structural problems is exacerbated by the institutional framework that we currently use to run the health system, and in particular, by Australia's current division of roles and responsibilities between the Commonwealth and the States. Therefore, even though our health system is performing pretty well on the whole, and changing the system cannot be without cost or risk, it is important to examine the options for where we want the system to end up - not as a distant pipe dream, but as a realistic alternative given practical realities and our history, culture and institutions.

Applying the principles in the last section to our current health system, two important shifts in the structure of the system become not only desirable, but probably inevitable. When we apply the subsidiarity principle, it becomes clear that the Commonwealth Government is going to continue to increase its responsibility for health policy and services, rather than reduce it. Quite apart from issues of funding, this is because of the strength of our national community interest in ensuring that there is equity throughout Australia in the availability and quality of health services; because health industries increasingly operate on a national basis, and both the health workforce and health service consumers are increasingly mobile; and because there are economies of scale to be captured in administering health services as a national system. The private health insurance industry and the pharmaceutical industry, for example, operate at the national level. Some of the services that have to be handled at a national level include cord blood banks and organ donations. Health education and medical training are national needs and are largely nationally funded. Recent crises in some state health systems over the qualifications and accreditation of health professionals 
highlight the increasing inappropriateness of trying to monitor and police such issues at a provincial level. If you think about who should be responsible for what, subsidiarity principles leave a great deal of responsibility with the Commonwealth.

The extent of the Commonwealth interest is then further underscored, of course, by the fact that two-thirds of all the public spending on health is already spending by the Commonwealth Government. Unlike other areas of public policy, where the Commonwealth has expanded its influence by stealth, in health it has been done by the express will of the Australian people - voting in 1946 to amend the Constitution to give the Federal Parliament power over the provision of pharmaceutical benefits, sickness benefits, hospital benefits, and medical and dental services (Constitution, section 51 (xxiiiA)). The present level of Commonwealth expenditure aligns with this historical reality, and public expectations about an efficient, seamless national health system that have only continued to strengthen.

The importance of the Commonwealth in the system is then further reinforced by pressure for movement towards a single funder arrangement. Faced with the current challenges, most economists agree that we would be better off moving from an arrangement where multiple governments provide the funds, tied to at times competing and conflicting priorities and accountabilities, to a single funder who can bring simplicity, consistency and efficiency. Most reformers in the health sector agree that a single funder would be better able to track the money so as to ensure that it follows the patient, rather than being constrained by strict functional or jurisdictional boundaries, or lost or redirected as it filters down through the system. In these ways, a single funder would facilitate more integrated and comprehensive planning, enhance the coordination of service delivery, improve value for money, increase the opportunity for seamless, patient-oriented services, and reduce cost-shifting and blame-shifting. These are highly relevant advantages for our system today.

There are four main options for who this single funder could be. The first would be to revert 100 years to a system where state governments are the single funder in their jurisdiction, but few regard this as realistic or desirable. A form of this option could work along the lines of the Canadian model, with a revenue-sharing agreement with the national government but all purchasing and delivery left to the States, but the fact is that, given all our history, we are not like Canada. Second, we could 'pool' Commonwealth and state funds, to then be administered by a 'joint' national health administration, which is a solution in the tradition of cooperative federalism, under the Council of Australian governments (COAG) framework. However, applying what we know about the strengths and weaknesses of 'connected government', this has all the problems of trying to have a shared arrangement for ongoing programs, which is very difficult to 
manage in practice, and is likely to be extremely hard to operate efficiently. The third option, involving other massive transformations of the system, is a 'managed competition' or voucher-based insurance system such as proposed by Scotton (2002), which I discuss elsewhere. Importantly for advocates of this option, it could not be introduced without the Commonwealth first becoming the single government funder (option four below), and then redirecting that funding into a system of insurance vouchers.

The fourth option - in my view, by far the most logical given all of the above - is that the Commonwealth Government move the relatively short distance from its current role, to that of also being the single funder. In practice, funding the entire system would mean retention by the Commonwealth of its current specific purpose grants to the States for health, plus around $37 \%$ of the $\$ 35$ billion (2003-04) paid annually to the States in the form of Goods and Services Tax (GST). This could be achieved by renegotiation of the GST agreement. State governments would be left in the same financial position as currently, since they would no longer have to spend the $\$ 13$ billion (2002-03) of their own-source funding currently expended annually on hospitals and other health services.

However, an important second structural shift is also implied in the evolution of our health system. Again applying the principle of subsidiarity and the other issues reviewed in the previous section, it is clear that even if we move towards a single national funder and clear Commonwealth regulatory control over the health system, the case remains for stronger regional and local involvement in the purchase and provision of these centrally-funded health services. Indeed, the case only becomes stronger. Therefore, while the subsidiarity principle translates into a very strong argument for a lot of health responsibilities to be handled at the national level, it also translates into an equally strong argument for most service delivery to be handled lower down, at the local or regional level. This includes all manner of delivery, including general practitioners, baby health clinics, pharmacies, hospitals, and nursing homes. Alongside the national government accepting the leadership role in setting the overall design principles of the system, and monitoring its performance, the problems of our current system would be addressed by introducing greater flexibility in the system at a lower level - lower than that of most of our present state governments. For these reasons, local and regional-level institutions would only become more important in the future.

Taking these two shifts together, Figure 9.2 sets out the structure of what a Commonwealth-funded public health system might look like. This structure would more clearly distinguish between who is funding the services, and the roles of purchasers and providers. It also remains a three-tiered system - national, regional and local - because local-level provision of health services remains vital. Essentially the Commonwealth would have the funding responsibilities at the 
national level and the oversight of the purchasing, but most purchasing would be at the regional level, and most of the services would be delivered either at the regional or local level. The major structural difference with current arrangements, in terms of service delivery, would be that these regional purchasers and/or providers, who control much of how services are designed and delivered in practice, would be unlikely to be a state government - other than perhaps in the case of Tasmania. In my view, they should be Commonwealth authorities, with a 'region' defined in line with the criteria already used by governments to determine the best scales at which to deliver these services.

Figure 9.2. What should a Commonwealth funded Public Health System look like?

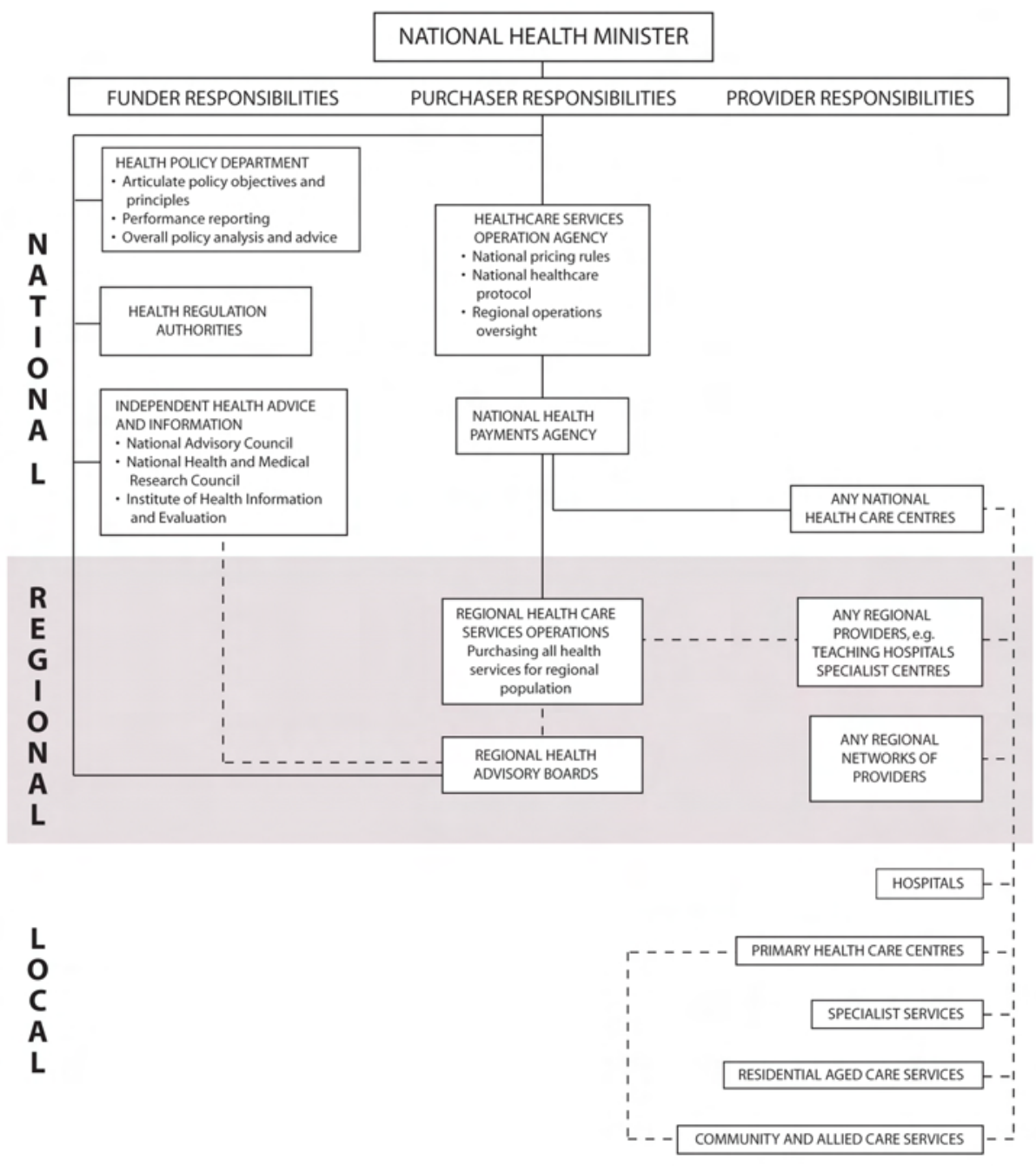


The next section discusses what this would mean in practice. Clearly there is little value in pretending that simply restructuring the system in these terms would suddenly fix all its problems or, in itself, meet all its challenges. A range of supplementary measures would be needed to ensure that any system works well, including this one as proposed. Some of these are already under way, such as the separation of funding, purchasing and providing - in ways that reinforce the need for a larger blueprint. What is clear is that if we ignore the options for systemic and institutional reform, we limit our own capacity to improve the system, whereas by considering them, we can hope to achieve sensible reforms including national principles for purchasing; greater ability to reallocate resources across and within regions in more flexible ways; increasing local involvement in service delivery; strengthening primary health care where it is needed; increasing the investment in preventive health strategies; strengthening cost control and accountability; and maximising the benefits of competition.

\section{The new regional level in health: new institutions?}

How would a reformed health system work in practice, particularly at the regional level? It goes without saying that it would mean institutional reform, but not constitutional reform, as it would rely on an existing range of familiar institutions. Even at the national level, there would be the need for new institutional infrastructure, rather than simply entrusting an increased range of responsibilities to the existing Commonwealth department.

The national administrative framework needs to be designed to meet a number of key requirements:

- political oversight and accountability;

- policy-advising capacity, well-informed by health and medical expertise;

- professional integrity in setting and administering regulatory standards;

- dedicated effort, appropriate management and technical expertise for operational matters, particularly for oversight of the nation-wide purchasing function.

The scale of these responsibilities would demand a number of separate agencies performing key roles, while working together within the policy framework set by the political leadership. The options for the national structure might include:

- a policy department responsible directly to the Minister for Health, advising expertly on the various health functions, health infrastructure, broad strategic issues, and general policy coordination;

- a suite of regulatory authorities, some of which already exist, overseeing separate but related areas of regulation including licensing of health products and providers, food standards, nursing home and residential facility standards, and the private health insurance industry; 
- an operational or executive agency, responsible for purchasing services at a national level and oversighting regional health service purchasers (see further below); and

- a strong national advisory body having links to advisory bodies associated with each of the major regulators, resources for independent research and independent reporting.

This national-level arrangement could draw very heavily on existing organisations, which would all be best placed in one portfolio, to aid policy coherence and coordination.

At the other end of the system - the local level - many institutional arrangements would not be substantially changed, even though the availability and quality of services should continually improve. At this level, the focus is on service provision. Most doctors and other professional health providers would continue to operate as independent private businesses and hospitals and aged care providers would continue to operate with a degree of independence as private or charitable organisations, or as public institutions with substantial management autonomy. However, some important changes could be expected over time. For example, a more integrated and patient-focussed approach will require further strengthening of primary care arrangements, with GP practices becoming increasingly multi-skilled, supported by nursing staff and linked more closely with allied health professionals as well as specialist medical practitioners. GP practices might effectively exercise increasing responsibility for the health care budget for their patients within the framework developed by regional purchasers. In rural and remote areas and for Indigenous communities, primary care services may be provided in more flexible and community-responsive ways, to address their particular needs and/or their unique problems in attracting skilled workers. Similarly, while hospitals would need to comply with minimum national standards and supervision, and be supported by the simplicity of uniform national purchasing requirements, they could ultimately be managed more flexibly according to the needs of the particular region. In community aged care services, there would be increased opportunity for regional purchasers to negotiate prime contracts with organisations responsible for networks of service providers delivering services in line with individuals' care assessments and customer-responsive authorisation. Over time, there would be opportunities for closer integration of community and residential aged care, and for services that allow more 'ageing-in-place' including more choice for the individuals concerned about their accommodation and services. For all major local publicly-owned facilities, there is a choice of governance models for delivering greater local responsiveness. The management of public hospitals should involve some direct interaction with the community, and ensure good community access; it should have the full confidence of clinical and professional staff; it needs to have 
sufficient critical mass to deliver acute care services safely and efficiently; and it needs the flexibility to go with the accountability for delivering services efficiently and effectively. The options include trusts within the framework of the national operations agency, with executive boards that include health expertise, business acumen and local community representation; or separate agencies each managed by a CEO appointed by the national operating organisation and responsible to it, with a strong advisory board. Indeed, governance models might vary between regions. Major local facilities might be Commonwealth-owned, regionally-owned, locally-owned or indeed privately owned; in any case, they would be subject to clear national regulation and their roles and requirements as service providers determined by contract with the regional purchasing authority.

The crucial link in obtaining the gains envisaged by a truly Commonwealth public health system of this kind, is at this regional level. The regional purchasers of health services would carry much of the responsibility for the increased flexibility under the new system. They provide the key to improving allocational efficiency in the system, through the incentive framework created by these regional purchasers having responsibility for the health objectives for their own population, and the flexibility to allocate funds according to their most cost-effective use. There would also be constraints: for example, national policy requirements such as co-payment limits and safety nets, nationally negotiated prices for particular services and oversight to guard against risks of poor management or inefficient responses to short-term pressures. However, consistent with these constraints is the clear scope for regional authorities to provide:

- close connections with providers and community organisations to ensure the purchasing is well-informed and responsive to regional requirements;

- clear accountability back to the national operational agency, and compliance with national policies; and

- $\quad$ sufficient clout to negotiate cost-effective deals with providers, including hospitals, nursing homes and specialists.

A crucial factor is that the regional population would be large enough for the authority to accept responsibility for the vast majority of health risks, thus driving the development of a holistic regional health strategy and integrated approaches to service design and purchase. The actuarial evidence is that purchasers could cover most variations in health risk if the population they are responsible for is around 200,000 or more. Given the variations in Australian demography, there is the possibility of around 20-30 regional purchasers, with the possibility of sub-regional arrangements to assist community responsiveness. This also has the advantage of being not too great a number of purchasers for the national operational agency to oversee. 
There are a number of options for the constitution of this regional health authority. My own preference would be for each regional purchaser to be under the direct control of the national operational agency, but with each also having a strong advisory board involving, in particular, the relevant GP Division(s) and other regional providers, and community organisations, possibly including local government representation. Some individual nominees selected by the Minister could also ensure a consumer voice and a sensible balance, without unduly politicising the board. The precise structure could draw heavily on current state regional health authorities and state and Commonwealth regional planning arrangements (e.g. for aged care); and draw upon - and, in time, influence - the structure and role of Divisions of GPs.

In time, the manner in which the regional purchaser is constituted might be influenced by, or evolve in line with, other regional governance arrangements within the federal system. It is not necessary, however, for the regional purchaser to be a constitutionally-recognised regional government in order to capture the benefits of competitive federalism, in which you still get the advantage of competition between different regions to provide better services to citizens. The efficiency and performance of regional health purchasing authorities, designing and contracting for services on behalf of the Commonwealth, would still be monitored and reported in the same way that the Productivity Commission now reports on the performance of state governments. It is, therefore, not clear that the purchaser needs to be a level of government, provided it is an agency with both flexibility and authority.

Clearly the staff of the regional authority would need to include health expertise as well as management expertise. The purchasing authority would have responsibility for paying for all services provided to residents in the region, wherever those services are provided (including, for example, high level acute services in a national centre outside the region). It would have a 'soft-capped' total budget based on the population's risk profile, with access to some specific national risk pools where the region cannot be expected to manage the risk on its own. The soft cap would also allow budget over-runs if necessary, where the consequences would be some form of performance review rather than penalising the regional population. The regional budget would identify estimates for component parts, but with specified levels of discretion where the regional purchaser can substantiate claims of savings in one component that might be better employed elsewhere, or can substantiate claims of the positive impact of a proposed investment on both health and costs. The degree of discretion might be widened in the light of proven performance over a period of several years. Regional purchasers could be expected to develop increasingly sophisticated approaches to managing the risks of sub-populations, particularly the various categories of chronically ill, drawing on the nationally developed protocols of best-practice, cost-effective care. Substantially increased funding of Indigenous 
communities could be expected, subject to monitoring improved health performance.

Regional purchasers would be required to publish annual reports on performance including health outcomes, service levels and financing, preferably supplemented by broader information reports by the national health statistics organisation for all regions.

As outlined earlier, the key advantages delivered by this arrangement would be not simply increased efficiency but, more importantly, increased responsiveness and flexibility. The regional authority might consider contracting with Divisions of GPs not only to provide support for GPs and for primary care planning in the regions, but also to manage the delivery of some allied or specialist services where the local (private) supply is not adequate. The regional purchaser may find it cost-effective to establish (or re-establish or restructure) associated primary care services such as maternity and child health clinics. It would be expected to move reasonably quickly to consider options for 'contracting out' or for 'centres of excellence' for particular procedures and activities to improve efficiency. It would explore with GPs, hospitals and other non-hospital providers the options for reducing the need for hospital care and building, or rebuilding hospital outreach services as a more cost-effective way of supporting patients. This may lead to reversing the decline in rehabilitation services, and in various outpatient services particularly in fields such as dialysis and cancer remediation.

What would this new or reconstituted regional level mean for the current state governments? In most cases, there would no longer be particular purpose or value in the state government attempting to own or run hospitals or other major health services, when these can be more efficiently run either privately, locally or as Commonwealth-owned facilities within the streamlined national system. Section 51 (xxiiiA) of the Constitution not only provides the Commonwealth with the power to make laws with respect to the provision of sickness and hospital benefits, but with respect to the provision of medical services, including owning and managing hospitals itself. Indeed its powers would extend to compulsory acquisition of state facilities for this purpose. However it would clearly be wise for the Commonwealth to negotiate the transfer of responsibility from the States, either to itself or to alternative local or regional providers, rather than attempting a compulsory take-over. The objective of a more seamless patient-oriented system would also suggest the transfer not only of hospitals, but other elements of state health systems. Of course, new boundaries would arise between the Commonwealth system and ongoing state and local community services systems, but these boundaries would not generally be as disruptive to patient care as the boundaries that currently exist within health. The model does not preclude the States from delivering health services purchased by a 
(Commonwealth) regional purchaser, and particularly in the medium term there could be benefit in drawing on state expertise in establishing the regions and supporting the planning work of regional purchasers. But, over time, the state role could be expected to fall away.

Importantly, the system would not be managed entirely from Canberra. It would have regional purchasers with the responsibility and flexibility to purchase the mix of services most appropriate to the region. They would be required to work closely with local community leaders and providers such as the GP Divisions. They would, however, work within the policy framework established nationally. Most services would be provided locally with a considerable degree of professional independence; services such as public hospitals would have management boards or trusts. Geographically large regions would need to have sub-regional planning structures and associated flexibility to allocate resources within the local area.

The potential benefits are clear, especially for rural and remote communities (see Podger 2007), but also less-advantaged urban communities. There would be transparency about the allocation of resources across regions and the ability to highlight regions receiving significantly less than their population needs deserve (relative to other regions). There would be greater flexibility to find local solutions to regional problems, blurring the current boundaries between hospitals, general practice and other forms of primary health care, and between medical services and aged care services. There would be room for informed choice by communities about services to be provided locally, and those to be accessed from specialist providers outside the area - making the trade-off, for example, between access and quality. These are all advantages that should be considered standard in a modern world-class health system. In Australia's case, strategic investment in orderly change and new institutions is needed to achieve them.

\section{Conclusions: systemic reform or ad hocracy?}

Reform of the kind advocated in this chapter would take time to implement, with many details open to debate and refinement. Moreover, there will be costs and risks in the transition. Accordingly, it is sensible to keep pursuing incremental changes in parallel with exploring the systemic change options. There are also natural limits to structural solutions and to the pace of reform, requiring attention also be given to the 'people issues' that will make a difference, including leadership and collaboration, and supporting systems and processes such as better information and transparency and genuine consultation. It is also important to remember that any new system will still have boundaries to manage, and is likely to involve all levels of government, even if some clearer division of responsibilities can be achieved. 
However, we should not be satisfied with incremental reforms alone, particularly if they smack of political ad hocracy rather than a clear and coherent longer term strategy that might make systemic reform easier in the future.

The shift towards a truly national health system, with new regional institutions and frameworks as one of its cornerstones, is not predicated on abolition of the federal system nor does it necessarily imply that the State governments disappear. State governments could choose to remain in the area of providing services, and continue to receive Commonwealth funding accordingly, but through the more transparent, accountable and efficient regime provided by the new national system. Equally, however, local government could become a much more major provider of local health services, again taking its funding direct from the Commonwealth through a single purchaser arrangement. Whoever provides the services, the focus of reform needs to be on improving the effectiveness and efficiency of the system when viewed nationally and when viewed from the regional level. The necessary financial resources need to be both centralised in the Commonwealth as the national funder, and then decentralised to regional purchasing authorities in a way consistent with genuine devolution of these important areas of public policy and services.

All of this is both necessary and achievable in the area of health, without constitutional reform, but with appropriate vision and commitment. Whether the lessons of subsidiarity and the limits of connected government, discussed earlier, also make similar reform appropriate to other areas of Australian public policy, is a question worth considering, but which is best left for others to answer.

\section{References}

Lindquist, E. A. 2000, 'Preconceiving from the centre: leadership, strategic review and coherence in public sector reform', in Organisation for Economic Cooperation and Development, Government of the Future, OECD, Paris, pp. 149-84.

Management Advisory Committee 2004, Connecting Government: Whole of Government Responses to Australia's Priority Challenges, Management Advisory Committee Report No. 4, Australian Public Service Commission, Canberra.

Menadue, J. 2000, Report of the NSW Health Council, NSW Government, Sydney. 2003, Better Choices, Better Health, Final Report of the South Australian Generational Health Review, Government of South Australia, Adelaide.

Podger, A. 2006a, 'Directions for Health Reform in Australia', in Productive Reform in a Federal System: Roundtable Proceedings 27-28 October 2005, Productivity Commission, Canberra, pp. 133-60. 
2006b, A Model Health System for Australia, Inaugural Menzies Health Policy Lecture, Menzies Centre on Public Health Policy, 3 March 2006; also published in three parts in Asia Pacific Journal of Health Management, 2006.

- 2007, 'Rural and Remote Implications of a New Structure for Australia's Health System', Presentation to National Rural Health Conference, Albury NSW, 10 March 2007.

Productivity Commission 1998, State, Territory and Local Government Assistance to Industry, Final Report, Canberra.

Scotton, R. 2002, 'The Scotton Model', in Productivity Commission, Managed Competition in Health Care, Workshop Proceedings, Canberra.

Smith, W. E. 1992, 'Planning for the Electricity Sector in Columbia', in Weisbord, M. R. (ed.), Discovering Common Ground, Berrett-Koehler Publishers, San Francisco. 